\title{
Inhibition of phosphodiesterase 5 reduces bone mass by suppression of canonical Wnt signaling
}

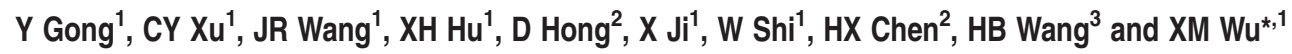

Inhibitors of phosphodiesterase 5 (PDE5) are widely used to treat erectile dysfunction and pulmonary hypertension in clinics. PDE5, cyclic guanosine monophosphate (cGMP), and protein kinase G (PKG) are important components of the non-canonical Wnt signaling. This study aimed to investigate the effect of PDE5 inhibition on canonical Wnt signaling and osteoblastogenesis, using both in vitro cell culture and in vivo animal models. In the in vitro experiments, PDE5 inhibition resulted in activation of cGMPdependent protein kinase 2 and consequent inhibition of glycogen synthase kinase $3 \beta$ phosphorylation, destabilization of cytosolic $\beta$-catenin and the ultimate suppression of canonical Wnt signaling and reduced osteoblastic differentiation in HEK293T and $\mathrm{C} 3 \mathrm{H} 10 \mathrm{~T} 1 / 2$ cells. In animal experiments, systemic inhibition of PDE5 suppressed the activity of canonical Wnt signaling and osteoblastogenesis in bone marrow-derived stromal cells, resulting in the reduction of bone mass in wild-type adult C57B/6 mice, significantly attenuated secreted Frizzled-related protein-1 (SFRP1) deletion-induced activation of canonical Wnt signaling and excessive bone growth in adult SFRP1 ${ }^{-1-}$ mice. Together, these results uncover a hitherto uncharacterized role of PDE5/cGMP/ PKG signaling in bone homeostasis and provide the evidence that long-term treatment with PDE5 inhibitors at a high dosage may potentially cause bone catabolism.

Cell Death and Disease (2014) 5, e1544; doi:10.1038/cddis.2014.510; published online 27 November 2014

In the canonical Wnt $(\mathrm{Wnt} / \beta$-catenin $(\beta$-cat)) signaling cascade, Wnt binds to Frizzled (Frz) receptors and the low-density lipoprotein receptor-related protein (LRP) 5 or 6, thereby activating dishevelled, suppressing the glycogen synthase kinase $3 \beta$ (GSK3 $\beta$ ) activity and inhibiting phosphorylation of $\beta$-cat at Thr41, Ser37, and Ser33 sites. The stabilized cytosolic $\beta$-cat enters the nucleus and consequently activates its downstream target genes via lymphoid enhancer-binding factor-1 (Lef-1) and T-cell factors. ${ }^{1,2}$ This signaling is finetuned in part via a negative feedback mechanism involving secreted and transmembrane Wnt inhibitors and activators, secreted Frz-related proteins (SFRPs), and Dickkopf-1 (Dkk1). ${ }^{3,4}$

Canonical Wnt signaling is critical not only to bone development in embryogenesis but also to the maintenance of bone mass during adult life. ${ }^{5}$ The initial evidence came from the discoveries that in humans loss- or gain-of-function mutations in LRP5 were linked with the osteoporosispseudoglioma syndrome and a high-bone-density syndrome, respectively. ${ }^{6-8}$ Subsequent studies in mice showed that Wnt signaling might promote ossification by inducing the differentiation of bone-forming osteoblasts, suppressing the development of bone-resorbing osteoclasts, and driving the differentiation of multi-potent stem cells toward an osteoblast cell fate. ${ }^{9}$
Non-canonical Wnt signaling is $\beta$-cat independent and consists of two main pathways: the Rho small GTPasesmediated planar cell polarity pathway and the $\mathrm{Wnt} / \mathrm{Ca}^{2+}$ pathway, ${ }^{10}$ involved in various aspects of cell fate differentiation and cell movement. Non-canonical Wnt signaling has profound effects on tissue morphogenesis in a variety of vertebrate species. ${ }^{10}$ The potential role for non-canonical Wnt signaling in bone formation has been investigated recently in limited studies, which have shown that the non-canonical WntGaq/11-PKC pathway operates in mammalian osteoprogenitors to promote osteoblast development, and that Wnt16 exhibits a stimulatory effect on bone metabolism. ${ }^{11-13}$ Nevertheless, the molecular events in the non-canonical Wnt signaling regulation of bone development and homeostasis have yet to be further elucidated.

Phosphodiesterases (PDEs) are a large family of enzymes that cleave cyclic nucleotides. To date, 11 PDE subtypes have been identified, among which PDE5 has been most extensively studied. PDE5, cyclic guanosine monophosphate (cGMP), and cGMP-dependent protein kinase (PKG) are among the major components of the non-canonical Wnt signaling pathway and are involved in the regulation of intracellular $\mathrm{Ca}^{2+}$ concentration. ${ }^{14,15}$ It is now well established that PDE5 degrades 3'-5' - cGMP and its inhibition leads to an increase in intracellular cGMP levels and activation of protein

\footnotetext{
${ }^{1}$ Department of Pharmacology, School of Medicine, Zhejiang University, Hangzhou 310058, China; ${ }^{2}$ Department of Orthopedics, Taizhou Hospital, Linhai 317000, China and ${ }^{3}$ State Key Laboratory of Reproductive Biology, Institute of Zoology, Chinese Academy of Sciences, Beijing 100101, China

${ }^{*}$ Corresponding author: XM Wu, Department of Pharmacology, School of Medicine, Zhejiang University, No. 688 Yuhangtang Road, Hangzhou 310058, China. Tel/Fax: +86 5718898 1121; E-mail: xiwu@ @ju.edu.cn

Abbreviations: $\mathrm{AP}$, alkaline phosphatase; $\beta$-cat, $\beta$-catenin; $\mathrm{BMSC}$, bone marrow-derived stromal cell; $\mathrm{BMTV}$, trabecular bone volume; cGMP, cyclic guanosine monophosphate; CK, casein kinase; Dkk1, Dickkopf-1; ED, erectile dysfunction; Frz, Frizzled; GSK3 $\beta$, glycogen synthase kinase $3 \beta$; Lef, lymphoid enhancer-binding factor; LRP5/6, low-density lipoprotein receptor-related protein 5 or 6; NOS, nitric oxide synthase; OSX, ostrix; PDE5, phosphodiesterase 5; PH, pulmonary hypertension; PKG, cGMP-dependent protein kinase; Runx2, Runt-related transcription factor 2; SFRP, secreted Frz-related protein; SS, sulindac sulfide; TbN, trabecular number; TbSp, trabecular separation; TbTh, trabecular thickness

Received 23.6.14; revised 22.10.14; accepted 23.10.14; Edited by M Agostini
} 
kinase $\mathrm{G}(\mathrm{PKG})$, resulting in a decrease in $\mathrm{Ca}^{2+}$ influx and consequent relaxation of smooth muscles, which produces the therapeutic effects in clinical erectile dysfunction (ED) and pulmonary hypertension $(\mathrm{PH}){ }^{14}$ Currently, little is known regarding the involvement of PDE5 in Wnt signaling regulation of bone formation and homeostasis. The objective of this study was to determine the effect of PDE5 inhibition on canonical Wnt signaling and bone mass.

\section{Results}

Involvement of PDE5 and PKG in canonical Wnt signaling. To examine the possibility of PDE5 and PKG in canonical Wnt signaling, we determined the effects of PDE5 and PKG inhibitors, and PDE5- and PKG-specific siRNAs on Lef1 reporter activity in 293 T cells. The two PDE5 inhibitors (i.e., tadalafil and vardenafil) used inhibited the Lef1-luciferase activity in a dose-dependent manner; at $10 \mu \mathrm{M}$, tadalafil and vardenafil decreased the reporter activity by 58 and $30 \%$, respectively, in the presence of control $L$ cellconditioned medium (L), and by 42 and $60 \%$, respectively, in the presence of Wnt3a-expressing cell-conditioned medium (Wnt3a) (Figure 1a and Supplementary Figure 1a). In contrast, KT5823, a potent inhibitor of PKG, dose dependently induced the Lef1-luciferase activity in 293 T cells; at $5 \mu \mathrm{M}$, it increased the reporter activity by $2.4-$ and 1.5 -fold, respectively, in the presence of control $L$ cell-conditioned medium and Wnt3a-expressing cell-conditioned medium (Figure 1b). Neither tadalafil nor KT5823 at the indicated concentrations affected the apoptosis of either $293 \mathrm{~T}$ cells or C3H10T1/2 cells, after $24 \mathrm{~h}$ treatments (Supplementary Figure 1c-e). To further confirm the specificity of PDE5 and PKG inhibitors in regulation of canonical Wnt signaling, we transfected the cells with either PDE5a or PKG siRNA and determined the Lef1 reporter activities. Wnt3a affected neither the cGMP levels nor the PDE5a expression (Figure 1e and Supplementary Figure 1b). PDE5a siRNA decreased PDE5a expression by $\sim 60 \%$ at the protein level and suppressed Lef1-luciferase activity by 15 and $45 \%$ in the presence of control $\mathrm{L}$ cell-conditioned medium and Wnt3aexpressing cell-conditioned medium, respectively (Figures 1c and e). PKG1 and PKG2 siRNAs, each lone, reduced PKG1 and PKG2 protein contents by 60 and $90 \%$, respectively, whereas the combination of PKG1 and PKG2 siRNAs reduced PKG1 and PKG2 protein contents by 70 and $80 \%$, respectively (Figure 1f). Silencing of PKG2 but not PKG1 resulted in a decrease in Lef1-luciferase activities by 20 and $33 \%$ in the presence of control $L$ cell-conditioned medium and Wnt3a-expressing cell-conditioned medium, respectively, and knockdown of both PKG1 and PKG2 decreased Lef1luciferase activities by $\sim 70$ and $75 \%$ in the presence of the two conditioned media, respectively (Figure 1d). Thus, inhibition of PDE5 negates canonical Wnt signaling, in line with this observation, and suppression of PKG, especially PKG2, induces canonical Wnt signaling in either the presence or absence of Wnt3a.

Effects of PDE5 inhibition on $\beta$-cat expression and stabilization. Given that $\beta$-cat is the central signal transducer of the Wnt signaling pathway, we evaluated the effect of PDE5 inhibition on $\beta$-cat messenger RNA (mRNA) abundance and protein content, and stabilization in 293 T cells, to further assess the possible involvement of PDE5 in Wnt signaling. PDE5 inhibitor tadalafil did not significantly change $\beta$-cat mRNA levels at either 5 or $10 \mu \mathrm{M}$ but attenuated Wnt3a-induced increases in $\beta$-cat protein levels in whole-cell lysates, cytosolic, and nuclear fractions by 58,60 , and $65 \%$, respectively, at $10 \mu \mathrm{M}$ (Supplementary Figure 2a and Figure 2a). Immunostaining further confirmed the effect of tadalafil on $\beta$-cat protein content; at $10 \mu \mathrm{M}$, tadalafil decreased both cytosolic and nuclear $\beta$-cat protein levels in response to recombinant Wnt3a protein (Figure $2 \mathrm{~b}$ ). Thus, inhibition of PDE5 negates canonical Wnt signaling through decreasing $\beta$-cat levels.

Phosphorylation of $\beta$-cat at Ser45 by casein kinase- 1 (CK1) and at Thr41, Ser37, and Ser33 by GSK3 $\beta$ regulates its stabilization in the cytosol, and the phosphorylated $\beta$-cat is recognized by E3 ubiquitin ligase and undergoes proteolytic degradation. ${ }^{16}$ To determine the role of PDE5 in the stabilization of $\beta$-cat, we assessed changes in $\beta$-cat phosphorylation in 293T cells treated with tadalafil at $10 \mu \mathrm{M}$, in either the presence or absence of Wnt3a. Wnt3a slightly decreased the phosphorylation of $\beta$-cat at Ser45, whereas tadalafil showed no significant effect (Supplementary Figure 2b). Phosphorylation of $\beta$-cat at Ser33, Ser37, and Thr41 was reduced by Wnt3a (80\%) but induced by tadalafil (1.4-fold), and tadalafil was capable of reversing the negative effect of Wnt3a on $\beta$-cat phosphorylation (3-fold) (Figure 3a). In contrast, Wnt3a increased (2.5-fold) but tadalafil decreased $(40 \%)$ GSK3 $\beta$ phosphorylation at Ser9, and tadalafil was effective to attenuate the Wnt3a-induced GSK3 $\beta$ phosphorylation (60\%) (Figure 3a).

We also assessed the possible involvement of cGMP in the destabilization of $\beta$-cat. We observed that the cGMP analog, 8-Br-cGMP, increased $\beta$-cat phosphorylation by $40 \%$ at Thr 41 , Ser37, and Ser33, but decreased GSK3 $\beta$ phosphorylation by $50 \%$ at Ser9 in 293T cells (Figure 3b). Conversely, Wnt3a resulted in a decrease in $\beta$-cat phosphorylation (80\%) but an increase in GSK3 $\beta$ phosphorylation (2-fold) (Figure $3 b$ ). These effects of Wnt3a were robustly reversed by 8 -Br-cGMP (1.5-fold for $\beta$-cat and $70 \%$ for GSK3 $\beta$ ) (Figure $3 \mathrm{~b}$ ). We further evaluated the potential role for PKG2 in $\beta$-cat stabilization using the siRNA technology. PKG2-specific siRNA, PKG2si, reduced the expression of PKG2 by $70 \%$ and decreased $\beta$-cat phosphorylation by $40 \%$, but increased GSK3 $\beta$ phosphorylation by $60 \%$ (Figure 3c). Moreover, PKG2si synergistically attenuated Wnt3a's inhibitory effect on $\beta$-cat phosphorylation $(66 \%)$ and potentiated Wnt3a's induction of GSK3 $\beta$ phosphorylation (50\%) (Figure 3c).

Finally, we performed reporter assays and co-immunoprecipitation to confirm GSK3 $\beta$ signaling as a downstream event of PDE5/cGMP/PKG2 signals in the regulation of $\beta$-cat stabilization. GSK3 $\beta$ inhibitor, SB216763, increased Lef1-luciferase activity but showed no significant effect in the presence of tadalafil in 293T cells (Figure 3d). However, the presence of tadalafil had no effect on Wnt3a induction of Lef1luciferase activity in 293T cells expressing GSK3 $\beta$ siRNA (GSK3 $\beta$ si) where GSK3 $\beta$ protein content was decreased by $60 \sim 80 \%$ (Figures $3 e$ and f). In cells treated with Wnt3a alone, 
a

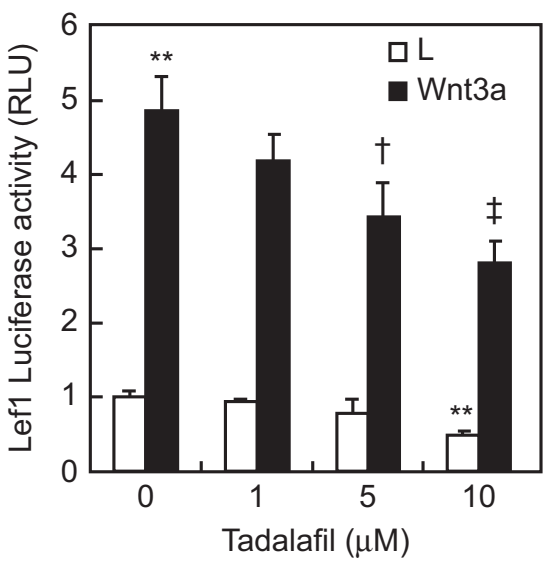

C

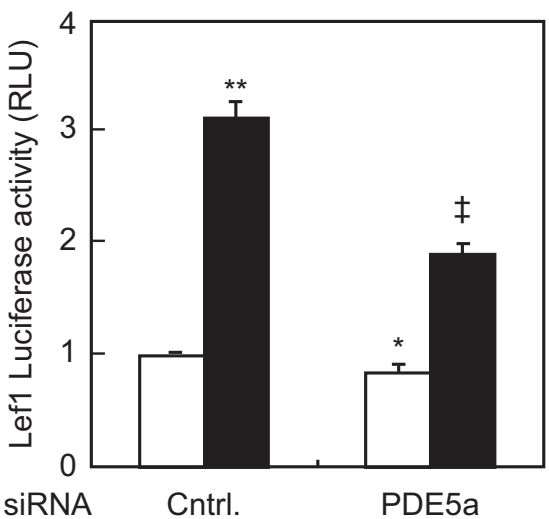

b

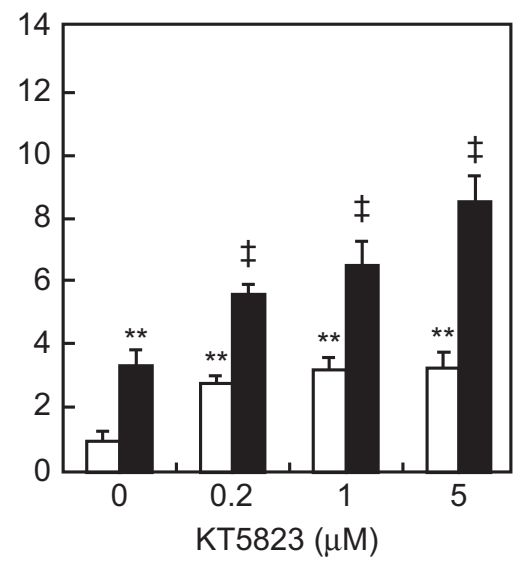

d

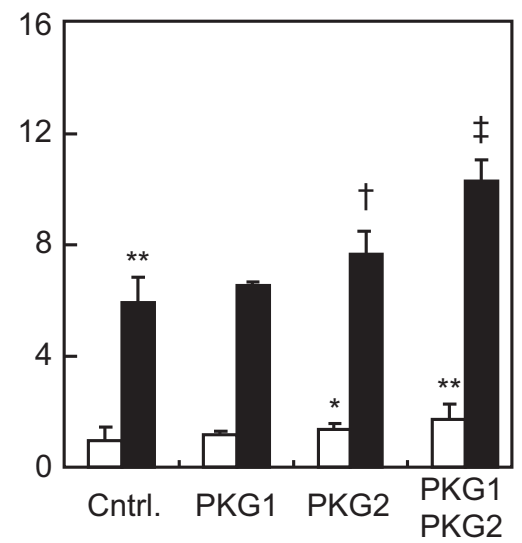

e

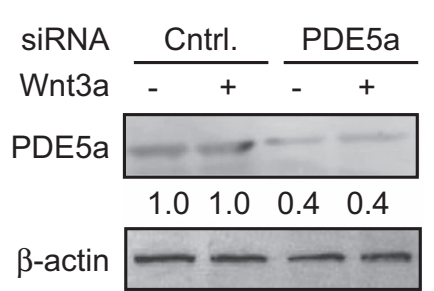

f

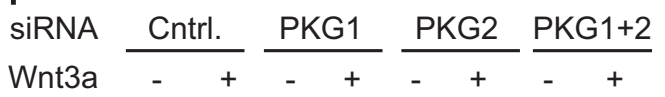

PKG1

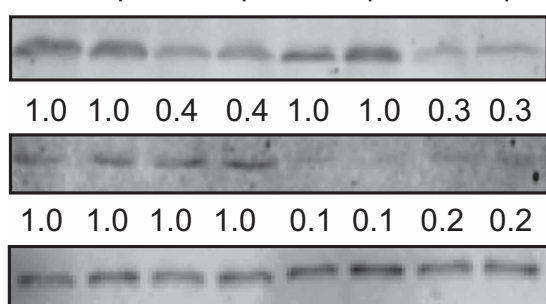

Figure 1 PDE5 and PKG2 regulates canonical Wnt signaling in 293T cells. (a and b) PDE5 inhibitor tadalafil and PKG inhibitor KT5823 affect the Lef1 luciferase activity. After co-transfection with the Lef1 luciferase and Renilla luciferase plasmids, $293 \mathrm{~T}$ cells were treated with indicated concentrations of either tadalafil or KT5823 for $24 \mathrm{~h}$ in the presence of either control $L$ cell-conditioned medium (L) or Wnt3a-expressing cell-conditioned medium (Wnt3a). (c and d) PDE5a, PKG1, and PKG2 siRNAs affect the Lef1 luciferase activity. After co-transfection with the reporter constructs and respective siRNAs, 293T cells were further cultured for $24 \mathrm{~h}$ in the presence of $\mathrm{L}(-)$ or Wnt3a $(+)$ conditional medium. (e and f) Protein levels of PDE5a, PKG1, and PKG2 in cells transfected with siRNAs. The signal form first band was defined as $1 .{ }^{*} P<0.05$, ${ }^{* *} P<0.01$ versus $L$ medium and vehicle treatments (or control siRNA); ${ }^{\dagger} P<0.05,{ }^{\ddagger} P<0.01$ versus Wnt3a medium and vehicle treatments (or control siRNA)

protein complex precipitated with a GSK3 $\beta$ antibody contained a considerable amount of PKG2; however, in cells treated with other test agents, protein complex contained a small amount of PKG2 in addition to GSK3 $\beta$, as expected (Figure $3 \mathrm{~g}$ ). Taken together, these observations suggest that activation of PKG2 by inhibition of PDE5 may suppress canonical Wnt signaling through inducing GSK3 $\beta$-mediated phosphorylation of $\beta$-cat at Thr41, Ser37, and Ser33 sites.
Effects of PDE5 inhibition on osteoblastic differentiation. To examine the role of PDE5 in osteoblastogenesis, we tested the effect of tadalafil on $\beta$-cat expression and osteoblastic differentiation in the presence or absence of Wnt3a in embryonic fibroblast C3H10T1/2 cells. Similar to what was observed in 293T cells, tadalafil at $10 \mu \mathrm{M}$ attenuated Wnt3a-induced increases in $\beta$-cat protein content in the whole-cell lysate, cystosolic, and nuclear 
a
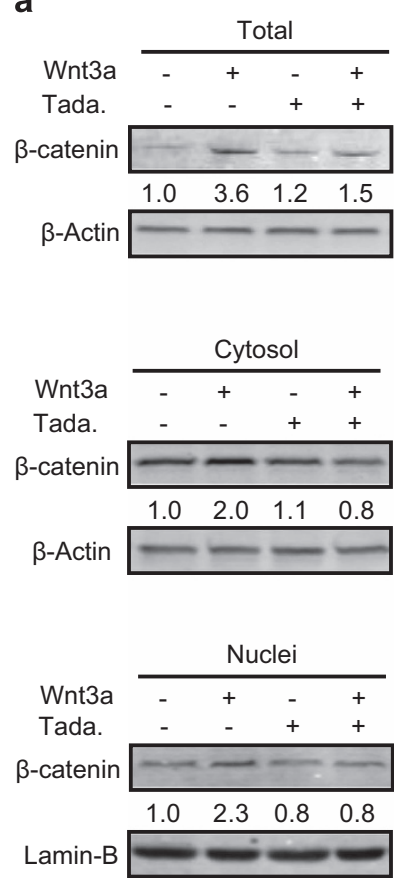

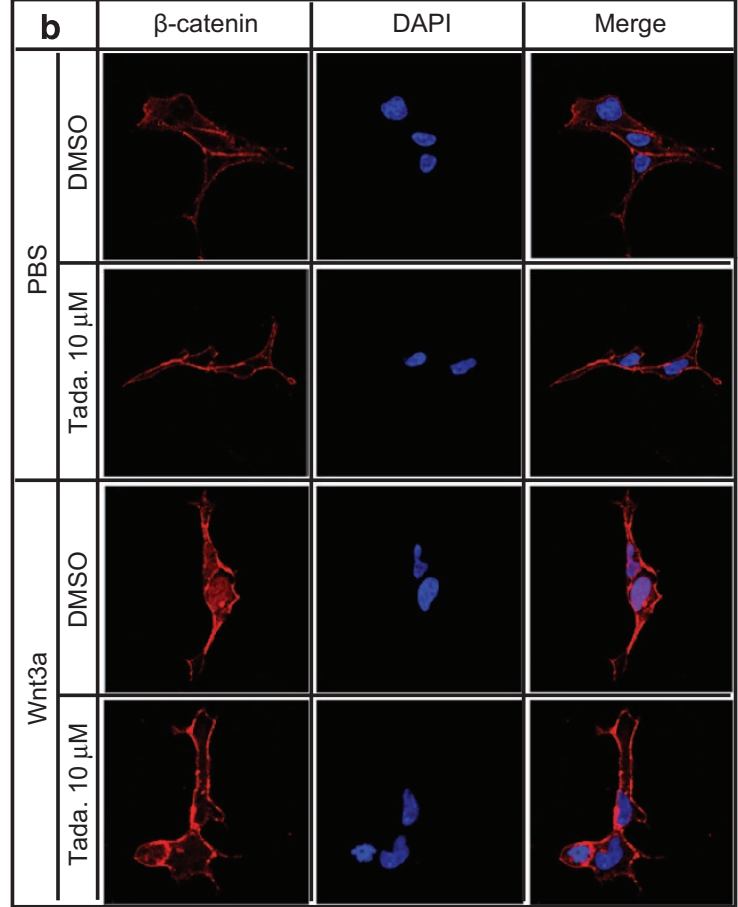

Figure $2 \beta$-Catenin levels in 293T cells treated with PDE5 inhibitor in the presence or absence of Wnt3a. (a) Tadalafil reduced $\beta$-catenin protein levels. Western blot analyses of $\beta$-catenin levels in whole cells, cytosolic, and nuclear fractions of $293 \mathrm{~T}$ cells treated with vehicle $(-)$ or tadalafil $(+)$ at $10 \mu \mathrm{M}$ in the presence of $\mathrm{L}(-)$ or Wnt3a $(+)$ conditional medium for $24 \mathrm{~h}$. (b) Immunofluorescence and confocal images of 293T cells treated with dimethyl sulfoxide (DMSO) or tadalafil at $10 \mu \mathrm{M}$ in the presence or absence of recombinant Wnt3a for $24 \mathrm{~h}$

by 48,50 , and $47 \%$, respectively, in C3H10T1/2 cells (Figure 4a). Moreover, Wnt3a not only increased mRNA levels of canonical Wnt signaling target genes including Lef1 and Dkk1 (Figures 4f and g) but also increased the differentiation of embryonic fibroblasts to osteoblasts as demonstrated by increases in mRNA levels of osteoblastogenic markers including alkaline phosphatase (AP), ostrix (OSX), and Runt-related transcription factor 2 (Runx2), as well as AP activities and mineralized nodule formation (Figures $4 \mathrm{~b}-\mathrm{i}$ ). Although tadalafil alone affected neither mRNA levels of AP, OSX, and Runx2 nor AP activities, it slightly reduced the baseline mRNA levels of Lef1 and Dkk1, and the mineralized nodule formation (Figures $4 \mathrm{~b}-\mathrm{i}$ ). In contrast, tadalafil reduced not only Wnt3a-induced increases in mRNA levels of Lef1 (72\%) and DKK1 (75\%) but also of osteoblastic markers including AP (74\%), OSX (86\%), and Runx2 (67\%), and AP activities (33\%) and formation of mineralized nodules $(30 \%)$ (Figures $4 \mathrm{~b}-\mathrm{i}$ ). Thus, in C3H10T1/2 cells, inhibition of PDE5 suppresses not only the canonical Wnt signaling but also the osteoblastogenesis in response to Wnt3a.

Decreases in bone mass after systemic inhibition of PDE5 in vivo. To assess the potential role of inhibition of PDE5 in bone mass in vivo, we first evaluated the effect of tadalafil on osteoblastogenesis and $\mathrm{Wnt} / \beta$-cat signaling in wild-type adult ( 2 months) C57BL/6 mice. Orally administered for 2 months at 45 or75 mg/kg daily that was 20- and 32-fold higher than the clinical dosage for ED (10 mg daily) and
5- and 8-fold higher than the clinical dosage for $\mathrm{PH}$ (40 mg daily), ${ }^{17,18}$ tadalafil robustly decreased the mass of cancellous bone but not of cortical bone as revealed by morphological and histological analyses (Figure 5a). Threedimensional reconstruction of the distal femur using micro computed tomography $(\mu \mathrm{CT})$ confirmed that tadalafil at both 45 and $75 \mathrm{mg} / \mathrm{kg}$ resulted in decreases in bone mineral density (BMD) by 30 and $35 \%$, in trabecular bone volume (BMTV) by 42 and $48 \%$, in trabecular number (TbN) by 35 and $50 \%$, but increases in trabecular separation (TbSp) by 58 and $97 \%$, respectively, while it had no effect on trabecular thickness (TbTh), when compared with the vehicle treatment (Figures 5a-c, and Supplementary Figure 3a and b). Moreover, tadalafil at 45 and $75 \mathrm{mg} / \mathrm{kg}$ reduced mRNA levels of Lef1 (34 and 49\%, respectively) and Dkk1 (24 and 56\%, respectively) in bone marrow-derived stromal cells (BMSCs) (Figures $5 f$ and $g$ ). In line with the inhibition of canonical signaling, tadalafil dose dependently reduced mRNA levels of osteoblastogenic markers including AP (18 and 38\%, respectively) and Runx2 (18 and 43\%, respectively) (Figures $5 d$ and e). Finally, tadalafil robustly decreased the numbers of not only Lef- and Dkk1-positive cells but also APand Runx2-positive cells as revealed by immunohistochemical staining of longitudinal sections of the distal femur (Figure 5h). Taken together, these results demonstrate that systemic inhibition of PDE5 may lead to robust inhibition of osteoblastogenesis and consequent reduction in bone mass possibly through inhibition of canonical Wnt signaling in adult mice. 

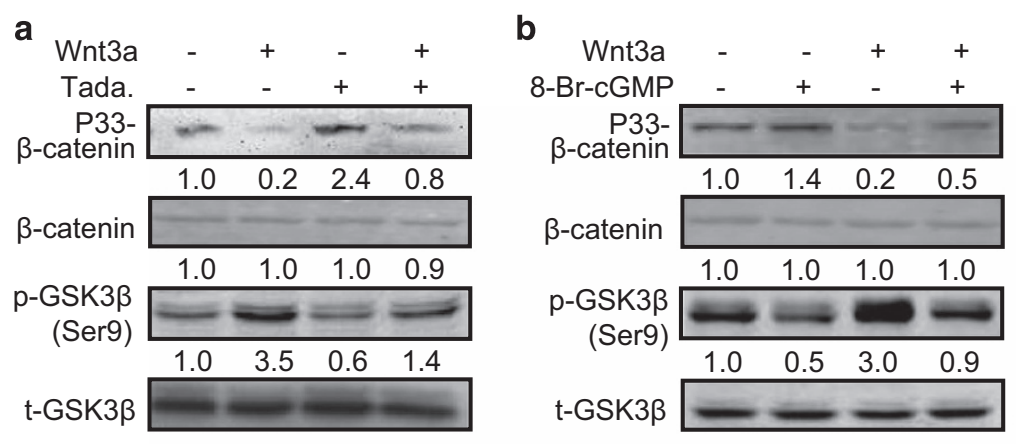

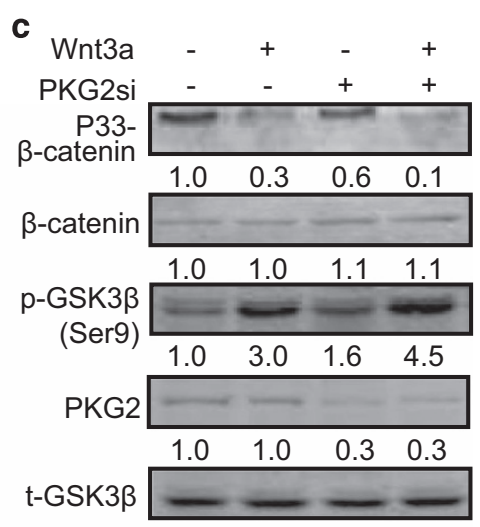

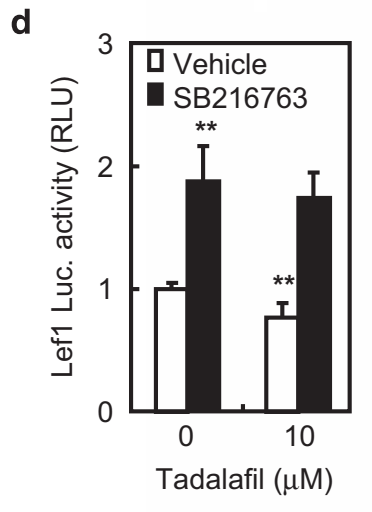

g

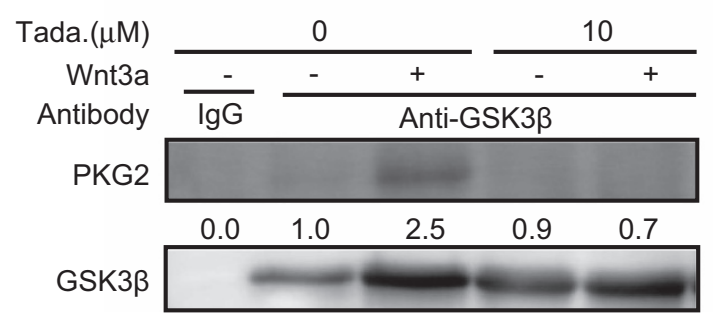

e

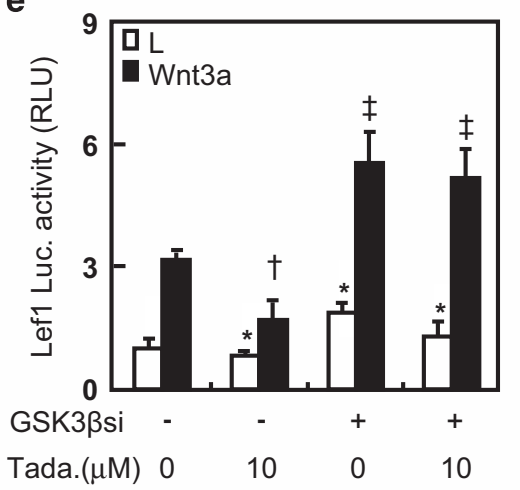

0

f
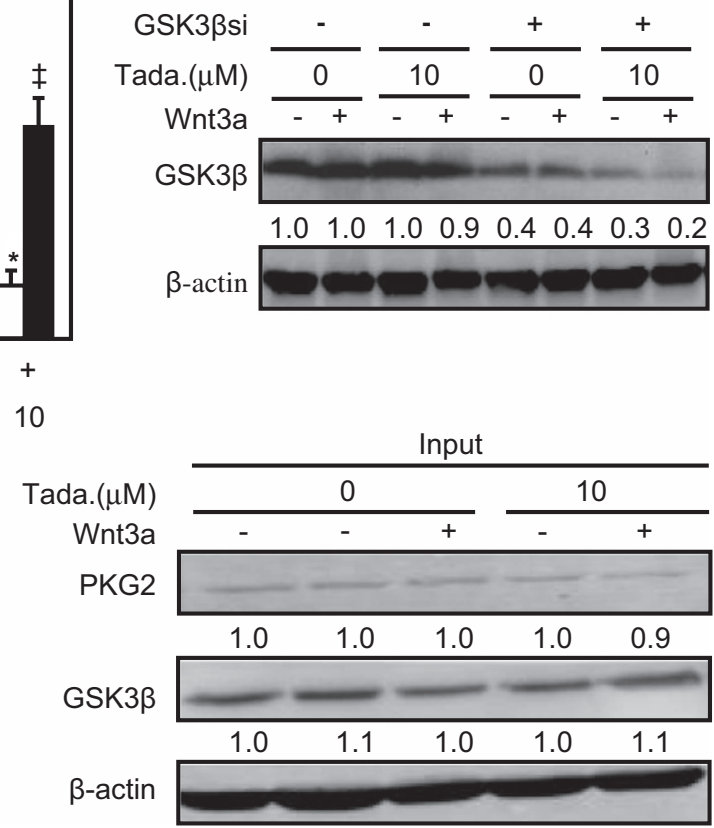

Figure 3 Stabilization of $\beta$-catenin affected by PDE5/cGMP/PKG2 signals in 293T cells. (a and $\mathbf{b}$ ) Tadalafil and 8-Br-cGMP affected the activation of GSK3 $\beta$ and stabilization of $\beta$-catenin. 293T cells were pretreated with vehicle $(-)$ or tadalafil $(+)$ at $10 \mu \mathrm{M}$ for $3 \mathrm{~h}$, then were stimulated with $\mathrm{L}(-)$ or Wnt3a $(+)$ medium in the presence of vehicle or tadalafil $(10 \mu \mathrm{M})$ for further $30 \mathrm{~min}$. p33- $\beta$-catenin, total $\beta$-catenin, p-GSK3 $\beta$ (Ser9), and total GSK3 $\beta$ were measured by western blottings. (c) PKG2 siRNA inhibited the activation of GSK3 $\beta$ and stabilization of $\beta$-catenin. 293T cells were transfected with siRNA for $48 \mathrm{~h}$, then were stimulated with $\mathrm{L}$ or Wnt3a medium in the presence of vehicle or tadalafil $(10 \mu \mathrm{M})$ for further $30 \mathrm{~min}$. (d and e) Effects of GSK3 $\beta$ inhibitor or its siRNA on Lef1 luciferase activities in 293T cells treated with or without tadalafil in the presence of L or Wnt3a conditional medium. (f) Protein levels of GSK3 $\beta$ in 293T cells transfected with its siRNAs. (g) Co-immunoprecipitation of endogenous GSK3 $\beta$ and PKG2. After various treatments, 293T cells were subjected to immunoprecipitation and western blot analyses by using the indicated antibodies. The signal from the first band was defined as 1 . ${ }^{*} P<0.05,{ }^{* *} P<0.01$ versus vehicle treatment and in the presence or absence of $L$ medium and control siRNA; ${ }^{\dagger} P<0.05,{ }^{\ddagger} P<0.01$ versus Wnt3a medium, vehicle, and control siRNA treatments

We next assessed the effect of tadalafil on osteoblastogenesis and Wnt signaling in 2-month-old SFRP1 knockout $\left(\mathrm{SFRP} 1^{-1-}\right)$ mice. At the baseline level, SFRP1 ${ }^{-/-}$mice had a significantly higher mass of cancellous bone but not cortical bone as compared with SFRP1 $1^{+/}$mice, as revealed by histological analysis of the longitudinal sections of the distal femur. At an oral dose of $75 \mathrm{mg} / \mathrm{kg}$ daily for 2 months, tadalafil robustly decreased the mass of cancellous bone but not in cortical bone in SFRP1 ${ }^{-/}$mice (Figure 6a). Threedimensional reconstruction of the distal femur using $\mu \mathrm{CT}$ further confirmed that there were significant increases in BMD (2.1-fold), BMTV (2.3-fold), and TbN (1.5-fold) but not in TbTh and TbSp in SFRP1 ${ }^{-1-}$ mice as compared with SFRP1 ${ }^{+/-}$ mice, and that tadalafil treatment resulted in significant decreases in BMD (38\%), BMTV (28\%), and TbN (47\%), but not in TbTh and TbSp as compared with the vehicle treatment (Figures 6a-c, and Supplementary Figure 4c and d). Likewise, BMSCs from SFRP1 ${ }^{-1-}$ mice formed much more mineralized nodules than those from SFRP1 ${ }^{+/}$mice (1.4-fold), and tadalafil attenuated SFRP1 knockout-associated excessive formation of mineralized nodules by $\sim 25 \%$ over vehicle (Figures 6d and e). Moreover, BMSCs from SFRP1 ${ }^{-/-}$mice exhibited higher transcription activities of Lef1 and Dkk1 (13- and 14-fold, respectively) than those from SFRP1 ${ }^{+/-}$ 
a
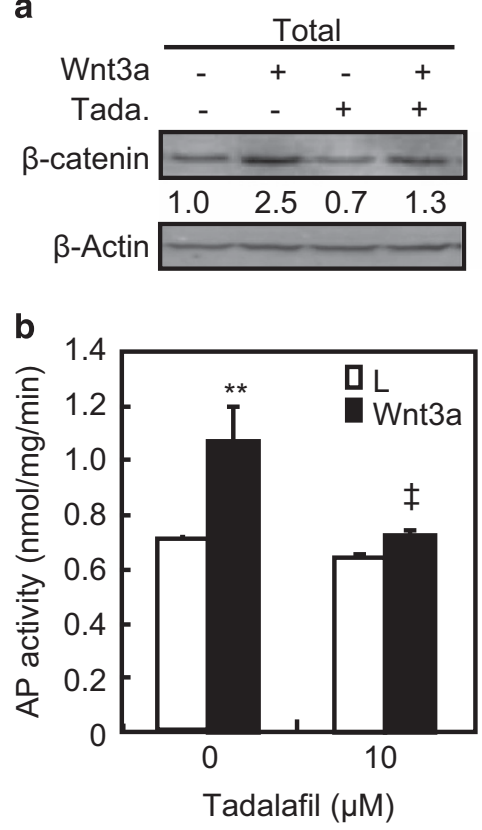

e

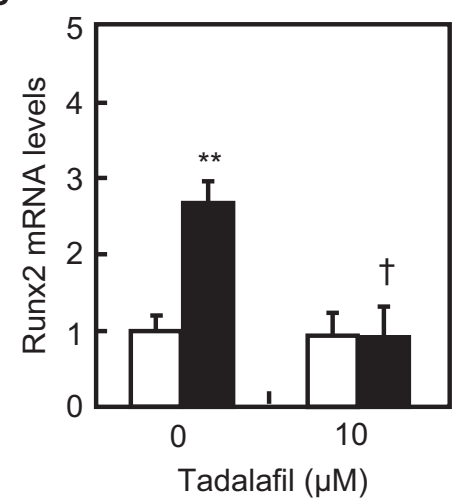

h

$\mathrm{L}$

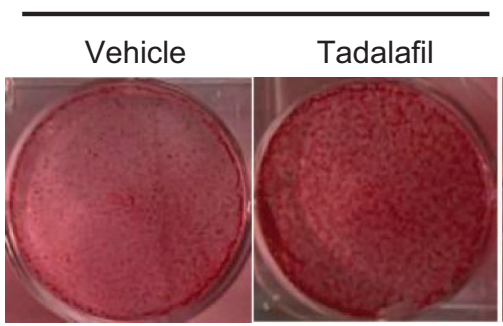

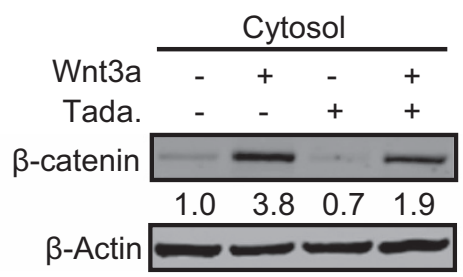

C

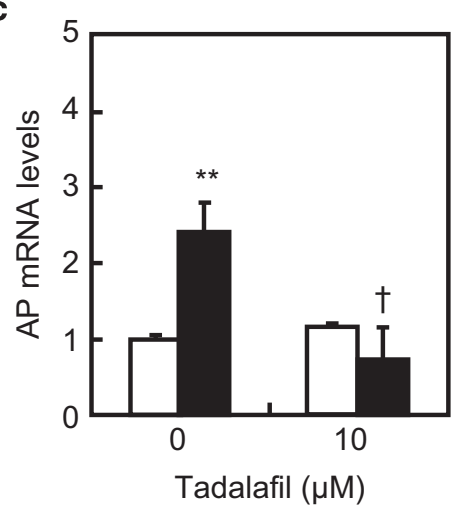

f
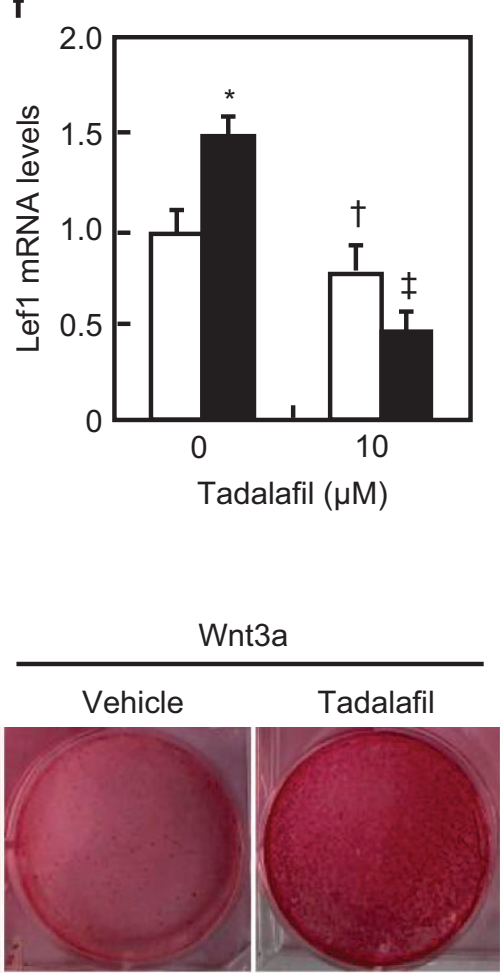

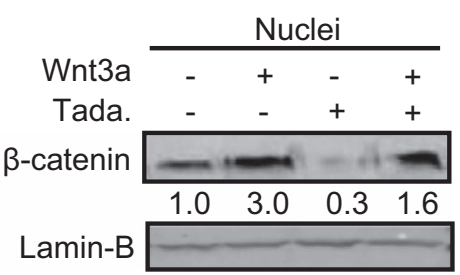

d

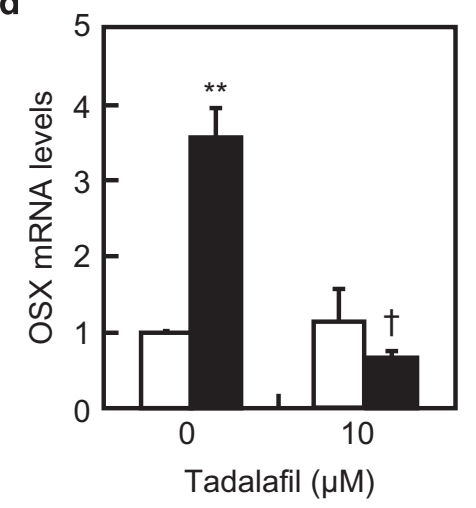

g

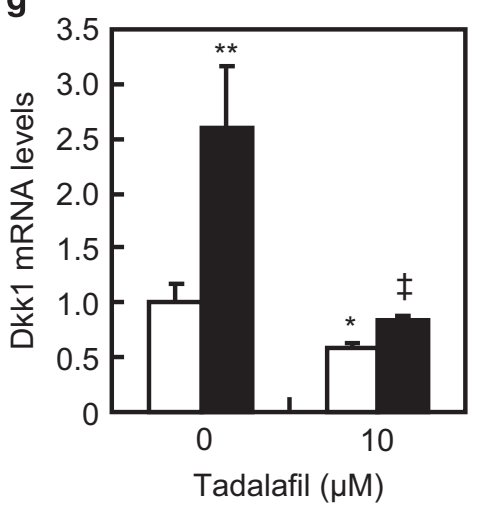

i

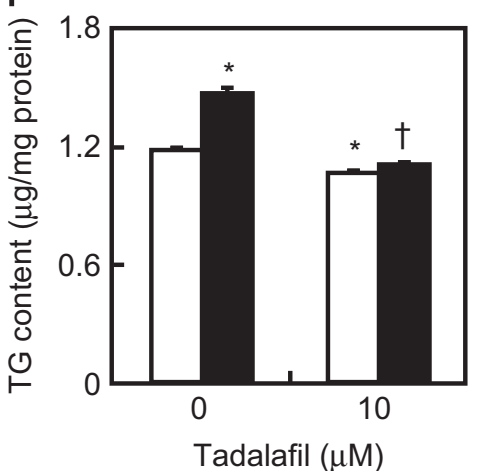

Figure 4 Inhibition of PDE5 suppresses the differentiation of osteoblast. (a) Tadalafil reduced $\beta$-catenin protein levels. Western blot analyses of $\beta$-catenin levels in whole cells, cytosolic, and nuclear fractions of $\mathrm{C} 3 \mathrm{H} 10 \mathrm{~T} 1 / 2$ cells treated with vehicle $(-)$ or tadalafil $(+)$ at $10 \mu \mathrm{M}$ in the presence of $\mathrm{L}(-)$ or Wnt3a $(+)$ conditional medium for $24 \mathrm{~h}$. $(\mathbf{b}-\mathrm{g})$ Expression of osteoblast differential markers and target gene of canonical Wnt signaling in C3H10T1/2 cells treated with tadalafil in the presence of $\mathrm{L}$ or Wnt3a medium. Cells were cultured in $\mathrm{L}$ or Wnt3a medium in the presence of vehicle or tadalafil at $10 \mu \mathrm{M}$ for $48 \mathrm{~h}$ followed by AP activity analyses and quantitative RT-PCR assays for mRNA levels of AP, OSX, Runx2, Lef, and Dkk1. (h and i) Tadalafil reduced the formation of mineralized nodules in response to Wnt3a medium. Cells were cultured in L or Wnt3a medium in the presence of ascorbic acid, $\beta$-glycerophosphate, and dexamethasone. After incubation for 21 days, cells were detected for bone nodules by alizarin-red staining and quantitative determination. The signal for the first western band was defined as $1 .{ }^{*} P<0.05,{ }^{* *} P<0.01$ versus $L$ medium and vehicle treatments. ${ }^{\dagger} P<0.05,{ }^{\ddagger} P<0.01$ versus Wnt3a medium and vehicle treatments 

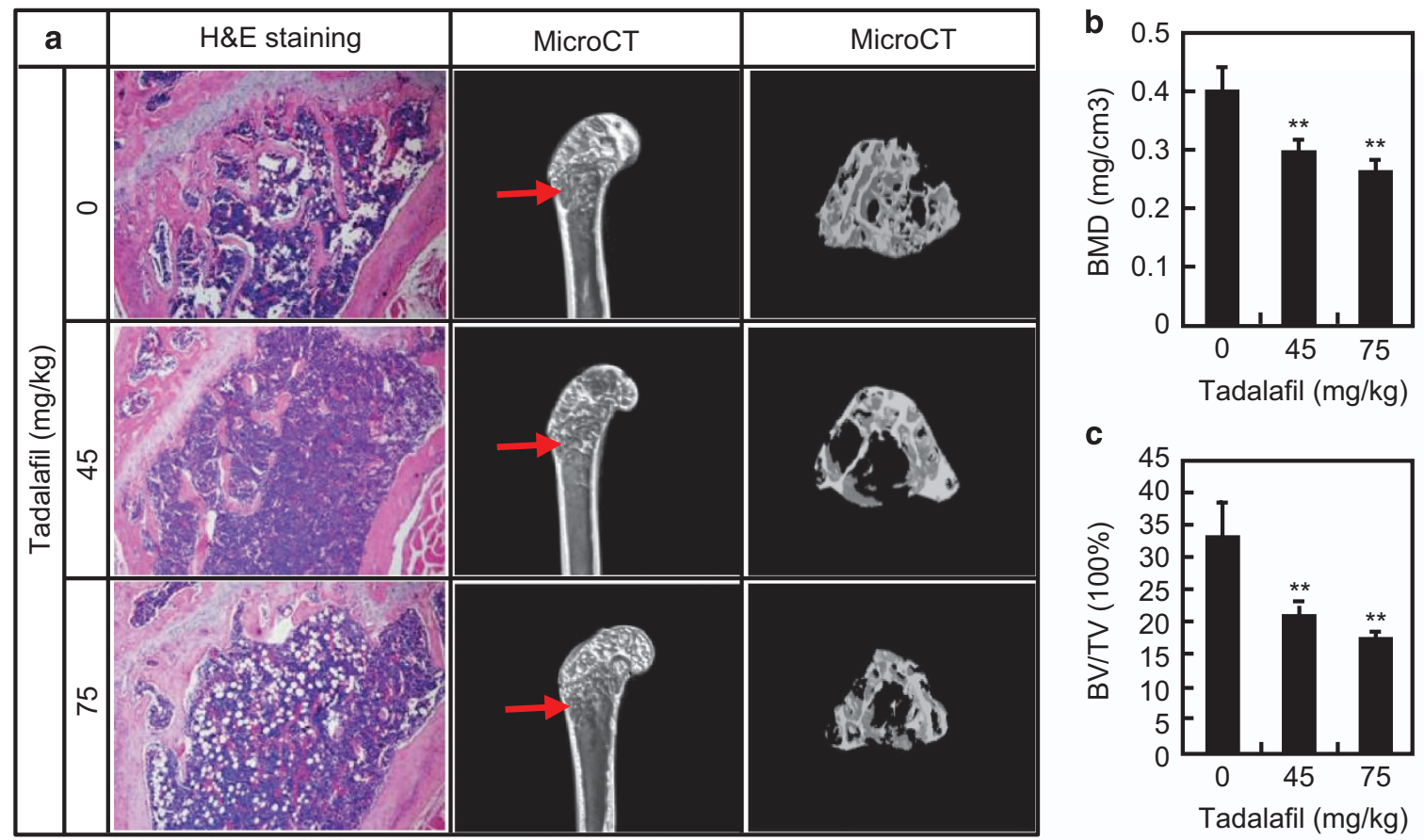

d

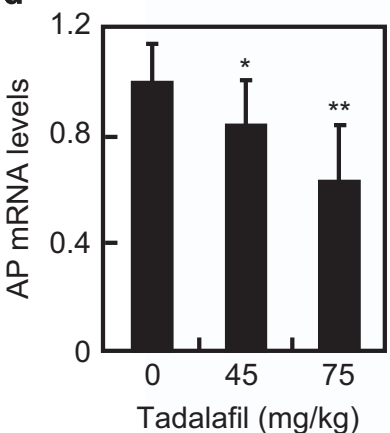

f

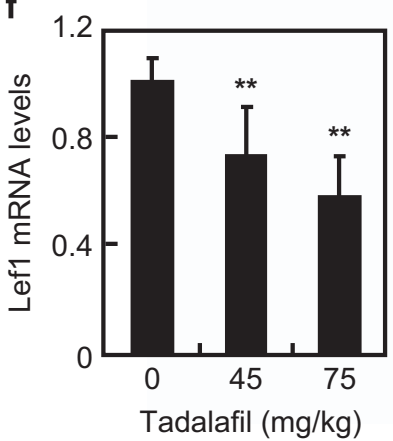

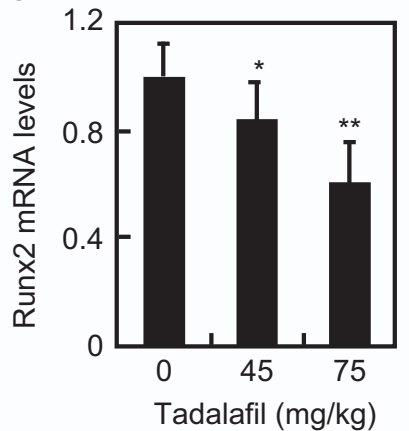

g

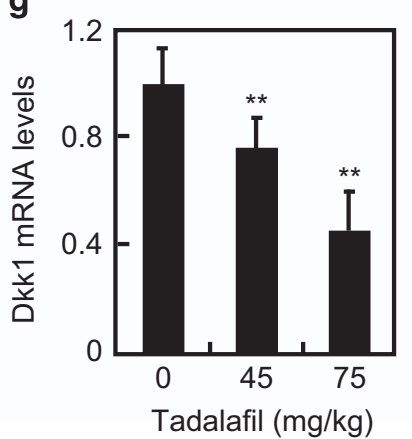

h

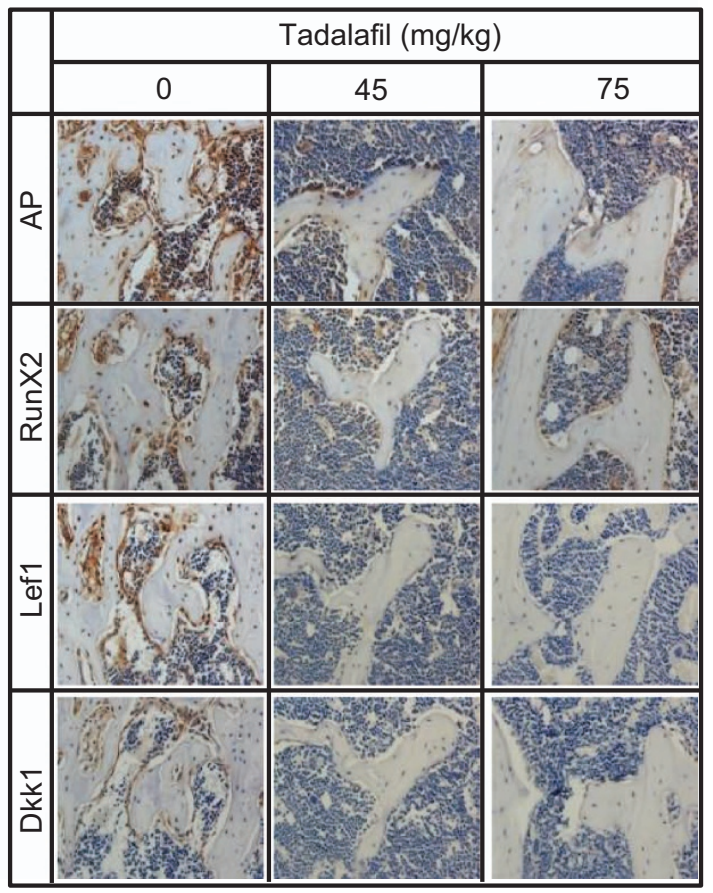

Figure 5 Tadalafil reduced bone mass in the adult wild-type mice. (a) Tadalafil reduced bone mass of distal femur in the adult mice. H\&E staining of paraffin sections and $\mu \mathrm{CT}$ analyses of the distal femur from mice intragastrically treated with normal saline or indicated dosages of tadalafil daily for 2 months. (b and $\mathbf{c}$ ) Quantification of bone parameters from three-dimensional reconstruction $\mu \mathrm{CT}$. (d-g) Tadalafil treatment reduced the mRNA levels of osteoblast marker genes (AP and RunX2) and target genes of canonical Wnt signaling (Lef1 and Dkk1) in BMSCs compared with the vehicle treatment. (h) Immunohistochemistry analyses of AP, Runx2, Lef1, and DKK1 expression in the distal femur of mice treated with vehicle or indicated dosages of tadalafil. ${ }^{\star} P<0.05,{ }^{* \star} P<0.01$ versus vehicle treatment.

mice, whereas systemic treatment with tadalafil in SFRP1 $1^{-1-}$ mice robustly attenuated the transcription of these genes (39 and 54\%, respectively; Figures $6 \mathrm{~h}$ and i). Similarly, BMSCs from SFRP1 ${ }^{-/-}$mice also exhibited higher transcriptional activities of osteoblast differential markers including AP and Runx2 (24- and 26-fold, respectively) than those from SFRP $1^{+/}$mice, and systemic treatment with tadalafil in SFRP1 ${ }^{-/-}$mice robustly attenuated the transcription of these 


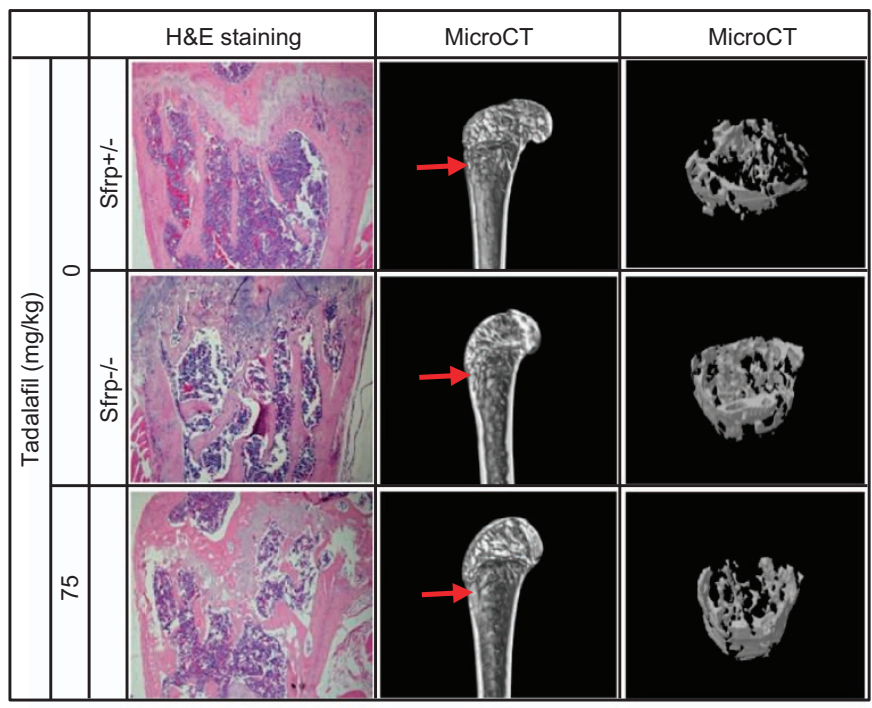

b

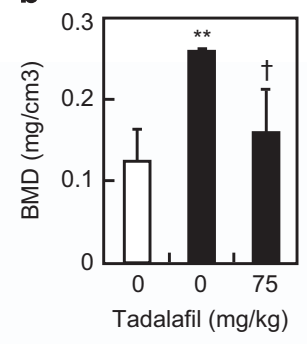

C

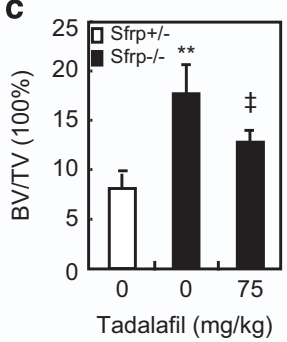

d

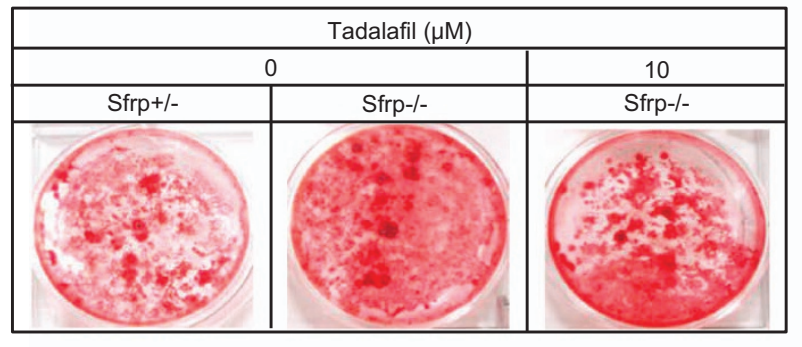

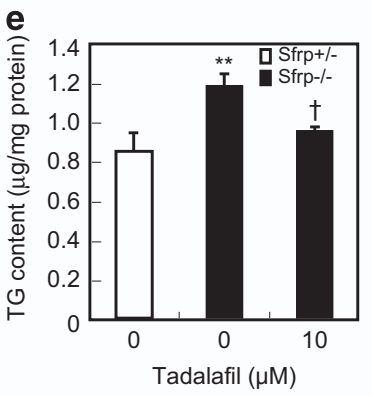

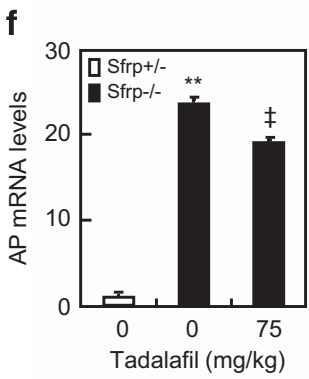

$\mathbf{g}_{35}$
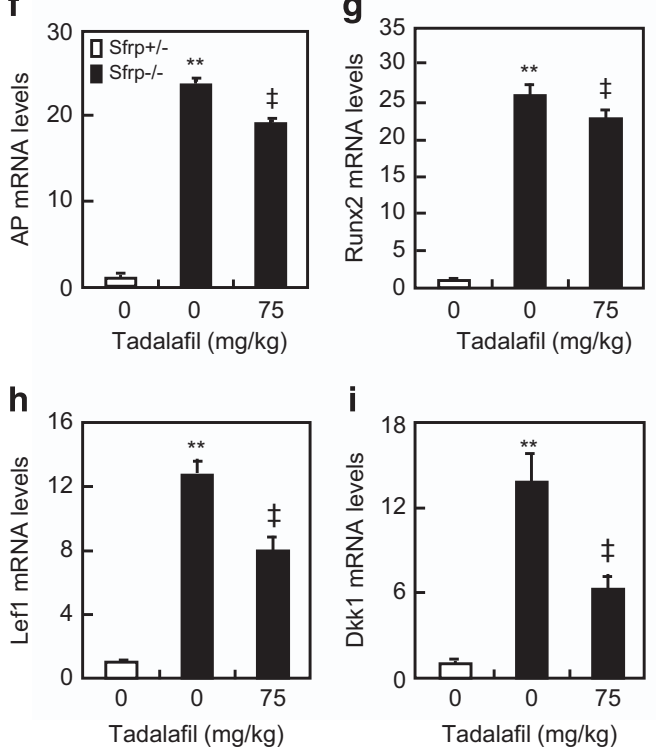

i

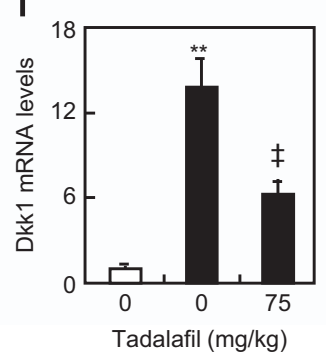

j

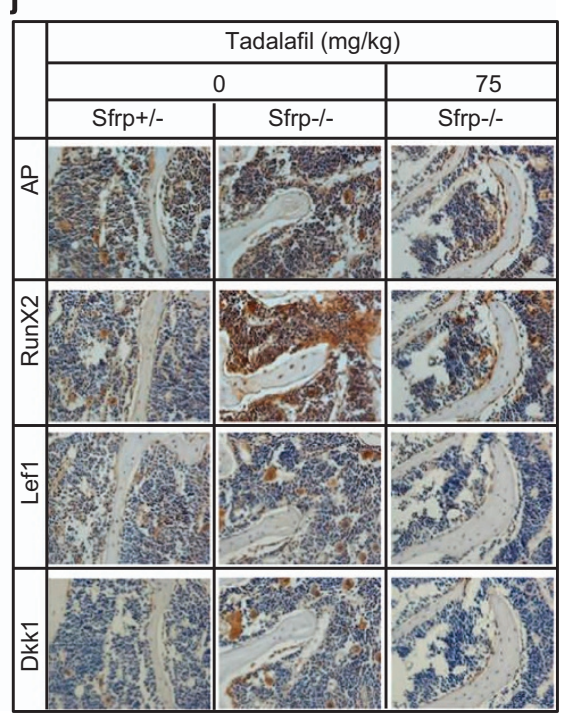

Figure 6 Tadalafil reduced bone mass in the adult SFRP1 $1^{-1}$ mice. (a) Tadalafil reduced bone mass of the distal femur in the adult SFRP1 $1^{-1}-$ mice. H\&E staining of paraffin
sections and $\mu \mathrm{CT}$ analyses of the distal femur from SFRP1 ${ }^{+1-}$ or SFRP1 $1^{-1}$ mice intragastrically administrated with normal saline or indicated dosage of tadalafil daily for 2 months. (b and $\mathbf{c}$ ) Quantification of bone parameters from three-dimensional reconstruction $\mu \mathrm{CT}$. (d and $\mathbf{e}$ ) Formation of mineralized nodules in BMSCs from the above mice. BMSCs were isolated from the indicated mice and were cultured in the media containing ascorbic acid, $\beta$-glycerophosphate, and dexamethasone in the presence or absence of indicated concentration of tadalafil. After incubation for 21 days, cells were detected for bone nodules by alizarin-red staining and quantitative determination. (f-i) Tadalafil treatment reduced the mRNA levels of osteoblast marker genes ( $A P$ and RunX2) and target genes of canonical Wnt signaling (Lef1 and Dkk1) in BMSCs from the femur and tibia of above mice. (h) Immunohistochemistry analyses of AP, Runx2, Lef1, and DKK1 expression in the distal femur of SFRP1 ${ }^{+/}$or SFRP1 ${ }^{-/}$- mice treated with vehicle or indicated dosages of tadalafil. ${ }^{*} P<0.05,{ }^{* *} P<0.01$ versus vehicle treatment. 
markers (21 and 16\%, respectively; Figures $6 f$ and g). As demonstrated by immunohistochemistry staining of the sections of the distal femur, deletion of SFRP1 in mice led to a robust increase in the numbers of Lef1- and Dkk1-positive cells, as well as AP- and Runx2-positive cells, and that systemic treatment with tadalafil in SFRP1 ${ }^{-/-}$mice robustly attenuated the increases in the number of not only Lef1- and Dkk1-positive cells but also AP- and Runx2-positive cells (Figure 6j). As indicated by tartrate-resistant acid phosphatase (TRAP) staining, neither deletion of SFRP1 nor systemic treatment with tadalafil had any significant effect on the number of TRAP-positive cells in SFRP1 ${ }^{-/}$mice (Supplementary Figure $3 a$ and $3 b$ ). Together, these results further confirm that systemic inhibition of PDE5 specifically reduces the excessive bone growth derived from forced activation of canonical Wnt signaling in adult SFRP1 ${ }^{-/-}$mice.

\section{Discussion}

By using wild-type C57BL/6 and SFRP1 knockout mice, we have uncovered that the PDE/cGMP/PKG2 signaling operates in conjunction with GSK3 $\beta$-mediated $\beta$-cat stabilization to regulate canonical Wnt signaling in maintenance of bone mass in adult mice in vivo. Using 293T and C3H10T1/2 cells, we have shown that inhibition of PDE5 induces cGMPdependent PKG2, which activates GSK3 $\beta$ and thereby destabilizes $\beta$-cat in the cytosol, resulting in inhibition of canonical Wnt signaling and consequent reduction of osteoblastic differentiation in vitro (Figure 7).

In one of our previous studies, we have demonstrated that Wnt3a through LRP5/6, Dvl, and most likely Frz receptors, activates a signaling module composed of Gaq/11 $\beta \gamma$-PI3KRac1-JNK2, resulting in stabilization of $\beta$-cat through phosphorylation at Ser191 and Ser605, and consequent localization to the nucleus. ${ }^{16}$ Here we show that PDE5 inhibition leads to activation of cGMP/PKG2, which destabilizes $\beta$-cat and consequently suppresses canonical Wnt signaling, supporting a role for the non-canonical pathway in the regulation of canonical Wnt signaling. ${ }^{19}$ The mechanisms underlying the activation of canonical versus non-canonical pathways by Wnt ligands are not fully understood. ${ }^{11}$ It has been suggested that the Frz2/Gai/PDE5/cGMP/PKG signaling module is an important component of non-canonical Wnt signaling in the activation of intracellular $\mathrm{Ca}^{2+}$ transient. ${ }^{15}$ Here we report that PDE5/cGMP/PKG signals are also involved in canonical Wnt signaling. It seems that non-canonical Wnt signaling and canonical Wnt signaling operate interactively and the binary distinctions of these two Wht pathways have come under scrutiny. As overexpression of Frz4 in HEK293 cells or Frz5 in Xenopus embryos is sufficient to transduce canonical signaling by Wnt5a, ${ }^{20,21}$ the specificity of the underlying signaling complexes may be dictated by the Frz receptor(s).

A previous study has observed that activation of Frz2 induces the cGMP-dependent phosdiesterase and decreases the intracellular cGMP levels, ${ }^{15}$ suggesting that Wnt3a fails to activate Frz2, and that PDE5/cGMP/PKG signals regulate canonical Wnt signaling independently of Wnt3a. The current study has shown that PDE5/cGMP/PKG2 signals regulate the stabilization of $\beta$-cat at the protein but not the mRNA level. Inconsistent to this observation, Li et al. ${ }^{22}$ and Tinsley et al. ${ }^{23}$

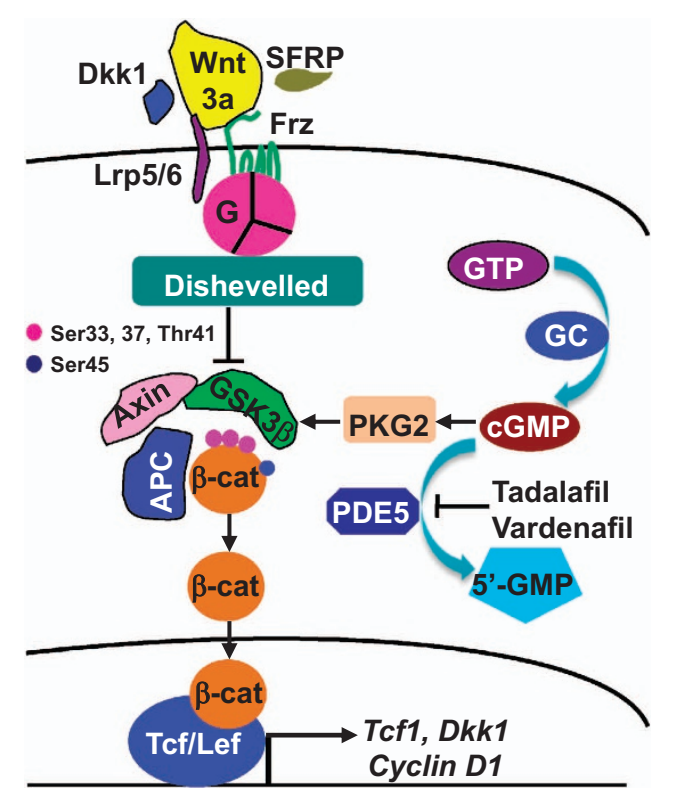

Figure 7 Schematic graph showing the proposed model for PDE5 inhibitionregulating canonical Wnt signaling and bone homeostasis. Inhibition of PDE5 by its inhibitors, such as tadalafil and vardenafil, results in elevation of CGMP and activation of cGMP-dependent protein kinase 2, which further activates GSK3 $\beta$ and thereby destabilizes $\beta$-catenin in the cytosol, leading to suppression of canonical Wnt signaling and the consequent reduction of osteoblastogenesis and bone mass. PDE5, phosphodiesterase 5; cGMP, cyclic guanosine monophosphate; GTP, guanosine-5'triphosphate; GC, guanylyl cyclase; 5'-GMP, guanosine-5'-monophosphate; PKG, cGMP-dependent protein kinase; Dkk1, Dickkopf-1; SFRP, secreted Frz-related proteins; Frz, Frizzled; LRP5/6, low-density lipoprotein receptor-related protein 5 or 6 ; G, G protein; GSK3 $\beta$, glycogen synthase kinase $3 \beta$; APC, adenomatous polyposis coli; $\beta$-cat, $\beta$-catenin; TCF, T-cell factors; Lef, lymphoid enhancer-binding factor

have shown that both non-steroidal anti-inflammatory drug, sulindac sulfide (SS), and PDE5 inhibitor, tadalafil, inhibit PDE5 activity and increase cGMP levels, resulting in PKG activation, decreased proliferation, and apoptosis through transcriptional suppression of $\beta$-cat, but not its proteolytic degradation in colon cancer cells, and more recently, Tinsley et al. ${ }^{24}$ have demonstrated that SS may trigger $\beta$-cat protein degradation and suppress $\beta$-cat gene transcription through increased phosphorylation in human breast cancer cells. The inconsistency is possibly due to the use of different cell types in the previous studies (i.e., cancer cells) and this study (i.e., normal cells).

Inhibition of PDE5 and activation of cGMP/PKG2 induce the phosphorylation of $\beta$-cat at Thr41, Ser37, and Ser33 but not at Ser45, suggesting that GSK3 $\beta$ but not CK1 may be downstream of the PDE5/cGMP/PKG2 signaling module. This notion is further supported by the findings that knockdown of PKG2 is sufficient to activate the phosphorylation of GSK3 $\beta$ and the stabilization of $\beta$-cat. Finally, PKG2 and GSK3 $\beta$ coexisting within one immunoprecipitated complex prompts us to speculate that PKG2 directly phosphorylates GSK3 $\beta$ in the complex. In line with this speculation, several recent reports have shown physical interactions between PKG2 and GSK3 $\beta$. In ATDC5 cells, PKG2 directly phosphorylates GSK3 $\beta$ to promote the hypertrophic differentiation. ${ }^{25}$ In UMR106 cells, PKG2 also phosphorylates the GSK3 $\beta$ at Ser9, and the 
apparent $K m$ of PKG2 for GSK3 $\beta$ is about $0.15 \times \mathrm{M}^{26}$ Thus, the present study has identified a mechanism in which activation of cGMP/PKG2 by inhibition of PDE5 results in GSK3 $\beta$ mediated destabilization of $\beta$-cat and consequent suppression of canonical Wnt signaling.

The role for canonical Wnt signaling in the embryonic development of bone is well established, but the function in maintaining the bone homeostasis in adulthood is less clear. $^{27,28}$ With regard to non-canonical Wnt signaling, little is known regarding its role in bone development and homeostasis in both embryogenesis and adulthood. ${ }^{11}$ Consistent with the role of PDE5/cGMP/PKG2 signaling in Wnt3ainduced osteoblastogenesis in vitro, systemic administration of a PDE5 inhibitor, tadalafil, reduces bone mass not only in normal but also in SFRP1 ${ }^{-1-}$ knockout adult mice in this study. The severe phenotype after tadalafil treatment reflects the importance of PDE5 activities in the maintenance of bone homeostasis. Endogenous Wnt signaling plays an important role in bone formation through stimulating the osteoblastogenesis and suppressing the adipogenesis and osteoclastogenesis. ${ }^{29}$ Our in vivo analyses show that: (1) inhibition of PDE5 reduces the trabecular bone but not the cortical bone, which is identical to the phenotypes of SFRP1 or LRP5 gain- and loss-of-function; ${ }^{30-32}$ (2) inhibition of PDE5 leads to the robust inhibition of Lef1 and Dkk1 transcription in BMSCs; (3) inhibition of PDE5 almost abolishes the SFRP1 knockout-producing overgrowth of bone; and (4) neither inhibition of PDE5 nor SFRP1 gain-of-function affects the osteoclastogenic activities. Together, these in vivo observations imply that inhibition of PDE5 attenuates not only the osteoblastogenic differentiation in response to Wnt3a but also the activities of canonical Wnt signaling, suggesting that inhibition of PDE5 reduces osteoblastogenesis possibly through suppressing canonical Wnt signaling.

Nitric oxide synthase (NOS) is the enzyme responsible for producing $\mathrm{NO}$ and $\mathrm{NO}$ activates soluble guanylyl cyclases to increase the intracellular cGMP levels and activate PKG. ${ }^{14}$ Consistent with our findings, previous studies have demonstrated that mice lacking endothelial NOS exhibit profound abnormalities in bone formation and a significant delay in osteoblastic differentiation, ${ }^{33,34}$ and that mice lacking either PKG2 or PKG1 may develop severe phenotypes; however, analyses of the skeletons of PKG2 but not PKG1 mutants have revealed the obvious defects in chondrogenesis but not in osteoblastogenesis. $^{25,35-39}$ It is likely that PKG2 and PKG1 play a functional redundancy in osteoblastogenesis.

In summary, the present study has demonstrated that PDE5 inhibition may cause bone mass loss involving non-canonical Wnt pathway, which operates interactively with canonical Wnt signaling in a way to destabilize $\beta$-cat through a cGMP/PKG2/ GSK3 $\beta$ signaling-dependent mechanism. Given that PDE5 inhibitors are commonly used in patients with ED and $\mathrm{PH}$, our findings may have significant clinical implications in alerting physicians of putative adverse effect of PDE5 inhibitors.

\footnotetext{
Materials and Methods

Chemicals and antibodies. Tadalafil and vardenafil were obtained from Selleckchem (Houston, TX, USA). KT5823, 8-Br(Bromo)-cGMP, Alizarin Red S, and SB216763 were from Sigma (St Louis, MO, USA). Recombinant murine Wnt3a protein was purchased from R\&D System (Minneapolis, MN, USA). Antibodies
}

against PKG1, PKG2, Lamin B, Dkk1, IgG, $\beta$-actin, and protein A/G PLUS-Agarose were from Santa Cruz Biotechnology (Santa Cruz, CA, USA). Antibodies against $\mathrm{p}$ - $\beta$-cat (Ser33/37/Thr41), p- $\beta$-cat (Ser45), $\beta$-cat, p-GSK3 $\beta$ (Ser9) and GSK3 $\beta$ were from Cell Signaling (Danvers, MA, USA). Antibodies against AP and RunX2 were purchased from Abcam (Cambridge, UK), and the antibody against Lef1 was from Proteintech (Chicago, IL, USA). The IRDye 680 and 800 second antibodies were from LI-COR Bioscience (Lincoln, Nebraska) and the Alexa 555-conjugated secondary antibodies were from Life Technologies (Grand Island, NY, USA). Cyclic GMP Direct Immunoassay kits were obtained from Abcam and TRAP staining kits were from Sigma.

Cell culture and conditioned medium preparation. C3H10T1/2 cells, Wnt3a-expressing and control $L$ cells, and HEK293T cells were all obtained from ATCC (Manassas, VA, USA). For maintenance, C3H10T1/2 cells and HEK293T cells were cultured, respectively, in Basal Medium Eagle (Life Technologies) and Dulbecco's modified Eagle's medium (Life Technologies) supplemented with $10 \%$ fetal calf serum (FCS, Life Technologies). Primary bone marrow stromal cells (BMSCs) were isolated from the femur and tibia, and cultured in alpha Minimum Essential Media (Life Technologies) with 15\% FCS as described previously. ${ }^{11}$ Conditional media were prepared from Wnt3a-expressing and control L cells, respectively, as described previously. ${ }^{16}$

Transient transfection and dual-luciferase assay. SV40 large T-antigen-expressing HEK cells (293T cells) were plated onto 24-well plates. Next day, they were transfected with $2 \mu \mathrm{g}$ Lef1 reporter construct using Lipofectamine 2000 reagent and $0.02 \mu \mathrm{g}$ Renilla luciferase construct (Promega, Madison, WI, USA) for $6 \mathrm{~h}$ in the absence of serum. ${ }^{40}$ In some cases, the cells were cotransfected with siRNA oligonucleotides targeting the test genes PDE5a, PKG1, $P K G 2$, and GSK3 $\beta$ (see Supplementary Table 1 for the specific sequence information), Lef1 reporter construct and Renilla construct. Transfectants were then cultured in a 1:2 diluted conditioned medium prepared from control $L$ cells or Wnt3a-expressing cells in the presence of tadalafil and/or vardenafil for $48 \mathrm{~h}$. At the end of the designated culture, cell lysates were prepared and dual-luciferase assay was performed according to the manufacturer's instructions (Promega). The firefly luciferase activity was normalized to the Renilla luciferase activity.

Western blotting, immunoprecipitation and immunocytochemistry. 293T and C3H10T1/2 cells were plated $1 \times 10^{4}$ and $1.5 \times 10^{4}$ cells $/ \mathrm{cm}^{2}$ overnight, after a variety of treatments. Cytosolic and nuclear fractions of cells were prepared by using NE-PER Nuclear and Cytoplasmic Extraction Reagents (Thermo Scientific, Waltham, MA, USA) as per the manufacturer's instructions. $\beta$-Actin and Lamin-B were used as the internal standards for the cytosolic and nuclear fractions, respectively. Western blot analysis and immunoprecipitation were performed using standard protocols and the immunoreactive signals for the proteins of interest were quantitated using the LI-COR Odyssey Infrared Imaging System (LI-COR Bioscience) and ImageJ (http://rsb.info.nih.gov/ij/). 293T cells seeded on chamber slides (Nalge Nunc International, Rochester, NY, USA) at $0.75 \times 10^{4} / \mathrm{cm}^{2}$ and cultured in regular medium overnight and in serum-free medium for $12 \mathrm{~h}$. After pretreatment with tadalafil for $2 \mathrm{~h}$, serum-starved cells were further stimulated with recombinant murine Wnt3a protein at $100 \mathrm{ng} / \mathrm{ml}$ in fresh serum-free medium for $30 \mathrm{~min}$. Cells were then immunostained with primary antibodies against $\beta$-catenin and subsequently counterstained with 4',6-diamidino-2-phenylindole. Immunoreactive protein signals were examined by confocal microscopy.

Osteoblast differentiation assay and quantitative RTPCR. C3H10T1/2 cells were seeded onto six-well plates. At confluence, cells were stimulated with conditioned medium prepared from control $L$ or Wnt3aexpressing cells for $48 \mathrm{~h}$ in the presence of vehicle or tadalafil. AP activity was determined and expressed as nanomoles of $p$-nitrophenol formed per minute per milligram of protein as previously described. ${ }^{41}$. For mineralization assays, confluent cells were incubated in the presence of $50 \mathrm{mg} / \mathrm{ml}$ ascorbic acid and $50 \mathrm{mM}$ $\beta$-glycerophosphate for 21 days. Total RNA was extracted using TRIzol reagent (Takara Biotechnology (Dalian) Co., Ltd., Dalian, China). mRNA levels of osteoblast markers and target genes of canonical Wnt signaling including Dkk1, Lef1, AP, Runx2, and Osx were determined by real-time PCR as previously described. ${ }^{42,43}$ GAPDH was included as an internal control and the relative levels of mRNA species of interest were calculated by the $2^{-\Delta \Delta C t}$ method. ${ }^{44}$ The primers used in our PCR analysis are presented in the Supplementary Information (Supplementary Table 2). 
Mouse strains, treatments and histological assessment. Male C57BL/6 mice were purchased from Shanghai SLAC Laboratory Animal Co. (Shanghai, China) and founder SPRP1 ${ }^{+/}$mouse strains were gifted by Dr Akihiko Shimono ${ }^{45}$ Two-month-old mice were orally administrated with tadalafil daily at 0 , 45 or $75 \mathrm{mg} / \mathrm{kg}$ for 2 months. We used $\mu \mathrm{CT}$ ( $\mu \mathrm{CT} 40$, Scanco Medical AG, Brüttisellen, Switzerland) for three-dimensional reconstruction and quantification of bone parameters, and reconstructed each image from one hundred $16-\mu \mathrm{m}$ slices immediately below the growth plate, with a threshold of $200 .^{46}$ Histological examination and immunohistochemistry staining were performed on paraffin sections $(4 \mu \mathrm{m})$ after decalcification. Immunohistochemistry staining was performed by using the Histostain-Plus Kit (Kangwei Reagents, Beijing, China) as described previously. ${ }^{47}$ After sequential treatments, tissue sections were sequentially incubated with normal serum for $30 \mathrm{~min}$, control $\mathrm{lgG}$ and primary antibodies against AP, Runx2, Lef1, or Dkk1 for $2 \mathrm{~h}$, and then HRP-conjugated secondary antibody for $30 \mathrm{~min}$. The diaminobenzidine solution was used for development of brown color and sections were counterstained with hematoxylin. The quantitative histomorphometry was performed using the Osteomeasure Analysis System (OsteoMetrics, Inc., Decatur, GA, USA). The Animal Studies Committee at Zhejiang University approved all mouse procedures.

Statistical analysis. Experiments were repeated at least three times. Numerical data were expressed as means \pm S.D. and analyzed by one-way ANOVA and Tukey-Kramer multiple comparisons test. Differences were considered significant when $P<0.05$. The SPSS statistical package (IBM, North Castle, NY, USA) was used.

\section{Conflict of Interest}

The authors declare no conflict of interest.

Acknowledgements. We thank Dr Akihiko Shimono of the National University of Singapore for the SFRP1 ${ }^{+/}$mice and Dr Ma at Washington University in St. Louis for the Lef1 reporter plasmid. This work was supported by the 973 Program (2011CB944403 to XMW), the National Natural Science Foundation of China (31071292 and 31271561 to XMW, and 81171748 to HC), and the Natural Science Foundation of Zhejiang Province, China (R2110269 to XMW).

1. Huelsken J, Birchmeier W. New aspects of Wnt signaling pathways in higher vertebrates Curr Opin Genet Dev 2011; 11: 547-553.

2. Wodarz A, Nusse R. Mechanisms of Wnt signaling in development. Annu Rev Cell Dev Biol 1998; 14: 59-88.

3. Cruciat CM, Niehrs C. Secreted and transmembrane wnt inhibitors and activators. Cold Spring Harb Perspect Biol 2013; 5: a015081.

4. Glinka A, Wu W, Delius H, Monaghan AP, Blumenstock C, Niehrs C. Dickkopf-1 is a member of a new family of secreted proteins and functions in head induction. Nature 1998; 391 : 357-362.

5. Minear $S$, Leucht $P$, Jiang J, Liu B, Zeng A, Fuerer $C$ et al. Wnt proteins promote bone regeneration. Sci Transl Med 2010; 28: 29ra30.

6. Gong Y, Slee RB, Fukai N, Rawadi G, Roman-Roman S, Reginato AM et al. LDL receptorrelated protein 5 (LRP5) affects bone accrual and eye development. Cell 2001; 107: 513-523

7. Boyden LM, Mao J, Belsky J, Mitzner L, Farhi A, Mitnick MA et al. High bone density due to a mutation in LDL-receptor-related protein 5. N Engl J Med 2002; 346: 1513-1521.

8. Little RD, Carulli JP, Del Mastro RG, Dupuis J, Osborne M, Folz C et al. A mutation in the $\mathrm{LDL}$ receptor-related protein 5 gene results in the autosomal dominant high-bone-mass trait. Am J Hum Genet 2002; 70: 11-19.

9. Canalis $\mathrm{E}$. Wnt signalling in osteoporosis: mechanisms and novel therapeutic approaches Nat Rev Endocrinol 2013; 9: 575-583.

10. van Amerongen R. Alternative Wnt pathways and receptors. Cold Spring Harb Perspect Biol 2012; 4: $a 007914$

11. Tu X, Joeng KS, Nakayama KI, Nakayama K, Rajagopal J, Carroll TJ et al. Noncanonical Wnt signaling through $\mathrm{G}$ protein-linked PKCdelta activation promotes bone formation. Dev Cell 2007; 12: 113-127.

12. Chen J, Tu X, Esen E, Joeng KS, Lin C, Arbeit JM et al. WNT7B promotes bone formation in part through mTORC1. PLOS Genet 2014; 10: e1004145.

13. Hendrickx G, Boudin E, Fijałkowski I, Nielsen TL, Andersen M, Brixen K et al. Variation in the Kozak sequence of WNT16 results in an increased translation and is associated with osteoporosis related parameters. Bone 2014; 59: 57-65.

14. Francis SH, Busch JL, Corbin JD, Sibley D. cGMP-dependent protein kinases and cGMP phosphodiesterases in nitric oxide and cGMP action. Pharmacol Rev 2010; 62: 525-563.
15. Ahumada A, Slusarski DC, Liu X, Moon RT, Malbon CC, Wang HY. Signaling of rat Frizzled-2 through phosphodiesterase and cyclic GMP. Science 2002; 298: 2006-2010.

16. Wu X, Tu X, Joeng KS, Hilton MJ, Williams DA, Long F. Rac1 activation controls nuclear localization of $\beta$-catenin during canonical Wnt signaling. Cell 2008; 133: 340-353.

17. Palit V, Eardley I. An update on new oral PDE5 inhibitors for the treatment of erectile dysfunction. Nat Rev Urol 2010; 7: 603-609.

18. Udeoji DU, Schwarz ER. Tadalafil as monotherapy and in combination regimens for the treatment of pulmonary arterial hypertension. Ther Adv Respir Dis 2013; 7: 39-49.

19. Ishitani T, Kishida S, Hyodo-Miura J, Ueno N, Yasuda J, Waterman M et al. The TAK1-NLK mitogen-activated protein kinase cascade functions in the $W n t-5 a / C a(2+)$ pathway to antagonize Wnt/beta-catenin signaling. Mol Cell Biol 2003; 23: 131-139.

20. Mikels AJ, Nusse R. Purified Wnt5a protein activates or inhibits $\beta$-catenin-TCF signaling depending on receptor context. PLOS Biol 2006; 4: e115.

21. He X, Saint-Jeannet JP, Wang Y, Nathans J, Dawid I, Varmus H. A member of the Frizzled protein family mediating axis induction by Wnt-5A. Science 1997; 275: 1652-1654.

22. Li N, Xi Y, Tinsley HN, Gurpinar E, Gary BD, Zhu B et al. Sulindac selectively inhibits colon tumor cell growth by activating the cGMP/PKG pathway to suppress Wnt $/ \beta$-catenin signaling. Mol Cancer Ther 2013; 12: 1848-1859.

23. Tinsley HN, Gary BD, Thaiparambil J, Li N, Lu W, Li Y et al. Colon tumor cell growth-inhibitory activity of sulindac sulfide and other nonsteroidal anti-inflammatory drugs is associated with phosphodiesterase 5 inhibition. Cancer Prev Res (Phila) 2010; 3: 1303-1313.

24. Tinsley HN, Gary BD, Keeton AB, Lu W, Li Y, Piazza GA. Inhibition of PDE5 by sulindac sulfide selectively induces apoptosis and attenuates oncogenic Wnt/ $\beta$-catenin-mediated transcription in human breast tumor cells. Cancer Prev Res (Phila) 2011; 4: 1275-1284.

25. Kawasaki $\mathrm{Y}$, Kugimiya $\mathrm{F}$, Chikuda $\mathrm{H}$, Kamekura $\mathrm{S}$, Ikeda $\mathrm{T}$, Kawamura $\mathrm{N}$ et al. Phosphorylation of GSK-3beta by cGMP-dependent protein kinase II promotes hypertrophic differentiation of murine chondrocytes. J Clin Invest 2008; 118: 2506-2515.

26. Zhao X, Zhuang S, Chen Y, Boss GR, Pilz RB. Cyclic GMP-dependent protein kinase regulates CCAAT enhancer-binding protein beta functions through inhibition of glycogen synthase kinase-3. J Biol Chem 2005; 280: 32683-32692.

27. Kim JB, Leucht $P$, Lam K, Luppen $C$, Ten Berge D, Nusse $R$ et al. Bone regeneration is regulated by wnt signaling. J Bone Miner Res 2007; 22: 1913-1923.

28. Krishnan V, Bryant HU, Macdougald OA. Regulation of bone mass by Wnt signaling. J Clin Invest 2006; 116: 1202-1209.

29. Baron R, Kneissel M. WNT signaling in bone homeostasis and disease: from human mutations to treatments. Nat Med 2013; 19: 179-192.

30. Bodine PV, Zhao W, Kharode YP, Bex FJ, Lambert AJ, Goad MB et al. The Wnt antagonist secreted frizzled-related protein-1 is a negative regulator of trabecular bone formation in adult mice. Mol Endocrinol 2004; 18: 1222-1237.

31. Clément-Lacroix P, Ai M, Morvan F, Roman-Roman S, Vayssière B, Belleville C et al. Lrp5independent activation of Wnt signaling by lithium chloride increases bone formation and bone mass in mice. Proc Natl Acad Sci USA 2005; 102: 17406-17411.

32. Kato M, Patel MS, Levasseur R, Lobov I, Chang BH, Glass DA et al. Cbfa1-independent decrease in osteoblast proliferation, osteopenia, and persistent embryonic eye vascularization in mice deficient in Lrp5, a Wnt coreceptor. J Cell Biol 2002; 157: 303-314.

33. Armour KE, Armour KJ, Gallagher ME, Godecke A, Helfrich MH, Reid DM et al. Defective bone formation and anabolic response to exogenous estrogen in mice with targeted disruption of endothelial nitric oxide synthase. Endocrinology 2001; 142: 760-766.

34. Aguirre J, Buttery L, O'Shaughnessy M, Afzal F, Fernandez de Marticorena I, Hukkanen M et al. Endothelial nitric oxide synthase gene-deficient mice demonstrate marked retardation in postnatal bone formation, reduced bone volume, and defects in osteoblast maturation and activity. Am J Pathol 2001; 158: 247-257.

35. Chikuda H, Kugimiya F, Hoshi K, Ikeda T, Ogasawara T, Shimoaka T et al. Cyclic GMP-dependent protein kinase II is a molecular switch from proliferation to hypertrophic differentiation of chondrocytes. Genes Dev 2004; 18: 2418-2429.

36. Koltes JE, Mishra BP, Kumar D, Kataria RS, Totir LR, Fernando RL et al. A nonsense mutation in cGMP-dependent type II protein kinase (PRKG2) causes dwarfism in American Angus cattle. Proc Natl Acad Sci USA 2009; 106: 19250-19255.

37. Lutz SZ, Hennige AM, Feil S, Peter A, Gerling A, Machann J et al. Genetic ablation of cGMPdependent protein kinase type I causes liver inflammation and fasting hyperglycemia. Diabetes 2011; 60: 1566-1576.

38. Weber S, Bernhard D, Lukowski R, Weinmeister P, Wörner R, Wegener JW et al. Rescue of cGMP kinase I knockout mice by smooth muscle specific expression of either isozyme. Circ Res 2007; 101: 1096-1103.

39. Schlossmann J, Feil R, Hofmann F. Insights into cGMP signalling derived from cGMP kinase knockout mice. Front Biosci 2005; 10: 1279-1289.

40. Mao J, Wang J, Liu B, Pan W, Farr GH, Flynn C et al. Low-density lipoprotein receptorrelated protein- 5 binds to Axin and regulates the canonical Wnt signaling pathway. Mol Cell 2001; 7: 801-809

41. Wu X, Zeng LH, Taniguchi T, Xie QM. Activation of PKA and phosphorylation of sodiumdependent vitamin $\mathrm{C}$ transporter 2 by prostaglandin E2 promote osteoblast-like differentiation in MC3T3-E1 cells. Cell Death Differ 2007; 14: 1792-1801.

42. Hu H, Hilton MJ, Tu X, Yu K, Ornitz DM, Long F. Sequential roles of Hedgehog and Wnt signaling in osteoblast development. Development 2005; 132: 49-60.

43. Wang $Y$, Tang $C$, Wu M, Pan Y, Ruan $H$, Chen $L$ et al. Dehydroascorbic acid taken up by glucose transporters stimulates estradiol production through inhibition of JNK/c-Jun/AP1 signaling in JAR cells. Mol Hum Reprod 2014; 20: 799-809. 
44. Kenneth JL, Thomas DS. Analysis of relative gene expression data using real-time quantitative PCR and the $2-\Delta \Delta C T$ method. Methods 2001; 25: 402-408.

45. Matsuyama M, Aizawa S, Shimono A. Sfrp controls apicobasal polarity and oriented cell division in developing gut epithelium. PLOS Genet. 2009; 5: el000427.

46. Hilton MJ, Tu X, Wu X, Bai S, Zhao H, Kobayashi T et al. Notch signaling maintains bone marrow mesenchymal progenitors by suppressing osteoblast differentiation. Nat Med 2008; 14: 306-314.

47. Chen L, Zhu H, Pan Y, Tang C, Watanabe M, Ruan $\mathrm{H}$ et al. Ascorbic Acid induces $\beta$ hCG production in human cytotrophoblasts and choriocarcinoma cells. J Clin Endocrinol Metab 2012; 97: 1667-1676.
Cell Death and Disease is an open-access journal published by Nature Publishing Group. This work is licensed under a Creative Commons Attribution 4.0 International Licence. The images or other third party material in this article are included in the article's Creative Commons licence, unless indicated otherwise in the credit line; if the material is not included under the Creative Commons licence, users will need to obtain permission from the licence holder to reproduce the material. To view a copy of this licence, visit http://creativecommons.org/licenses/by/4.0

Supplementary Information accompanies this paper on Cell Death and Disease website (http://www.nature.com/cddis) 